\title{
High level of clinical inertia in insulin initiation in type 2 diabetes across Central and South-Eastern Europe: insights from SITIP study
}

\author{
Matthew D. Campbell ${ }^{1,2}$ (D) Drazen Babic ${ }^{3} \cdot$ Uros Bolcina $^{3} \cdot$ Lea Smirčić-Duvnjak $^{4} \cdot$ Tsvetalina Tankova $^{5}$. \\ Asimina Mitrakou ${ }^{6} \cdot$ Peter Kempler $^{7} \cdot$ Andrej Janez $^{7}$
}

Received: 4 January 2019 / Accepted: 10 April 2019 / Published online: 16 April 2019

(c) The Author(s) 2019

\begin{abstract}
Aims Little is known regarding initiation of insulin therapy in type 2 diabetes (T2D) in Central and South-Eastern European countries. Therefore, we conducted a survey to characterise the prescribing practices of specialist diabetes healthcare professionals in this region and assessed factors that influence clinical decision-making regarding insulin initiation in T2D. Methods A cross-sectional survey sampled 211 specialist diabetes healthcare prescribers from five Central and SouthEastern European countries (Bulgaria, Croatia, Greece, Hungary, and Slovenia). A structured questionnaire was developed which surveyed current clinical practices and influencing factors, barriers to insulin initiation, and combination therapy prescribing preferences.

Result Only 9.4\% (20 of out of 211 respondents) of healthcare professionals would initiate insulin therapy in T2D patients at the recommended $\mathrm{HbA} 1 \mathrm{c}$ threshold of 7-7.9\% [53-63 $\mathrm{mmol} / \mathrm{mol}]$. Large regional differences were evident in insulin initiation thresholds ( $\geq 9.0 \%$ [ $\geq 75 \mathrm{mmol} / \mathrm{mol}]$ : Bulgaria $80.8 \%$ vs. Slovenia $13.3 \%$ ). Psychological distress was recorded as the major barrier to insulin initiation. Health insurance regulations were ranked more important than personal clinical experience and clinical guidelines in clinical decision-making. Information from peers was more influential than manufacturer information, clinical experience, and continuous medical education, respectively, for insulin initiation.

Conclusions Despite large regional variation, there is widespread delay of insulin initiation from specialist diabetes healthcare professionals in Central and South-Eastern Europe.
\end{abstract}

Keywords Insulin therapy initiation $\cdot$ Type 2 diabetes mellitus $\cdot$ Clinical inertia

Managed By Massimo Federici.

Electronic supplementary material The online version of this article (https://doi.org/10.1007/s00592-019-01346-1) contains supplementary material, which is available to authorized users.

Matthew D. Campbell and Drazen Babic: Joint first authors.

Matthew D. Campbell

m.d.campbell@leeds.ac.uk

1 School of Food Science and Nutrition, University of Leeds, Leeds, UK

2 Multidisciplinary Cardiovascular Disease Research Group, University of Leeds, Leeds, UK

3 Diabetes Education and Research Institute AGADA, Ljubljana, Slovenia

4 University Clinic for Diabetes, Endocrinology and Metabolic Diseases Vuk Vrhovac, Merkur University Hospital, Zagreb, Croatia

\section{Introduction}

Type 2 diabetes (T2D) is one of the greatest global health emergencies of today with almost a half a billion people living with the disease [1]. To lessen the burden of T2D, there is an urgent need for responsive, responsible, and effective

5 Clinical Centre of Endocrinology, Medical University, Sofia, Bulgaria

6 1st Department of Medicine, Semmelweis University, Budapest, Hungary

7 Department of Endocrinology, Diabetes and Metabolic Diseases, University Medical Centre, Ljubljana, Slovenia 
clinical care. Through large clinical trials, it is understood that intensive glucose control prevents microvascular complications [2] and improves cardiovascular outcomes [3] in adults with T2D. In Europe, as well as the USA [4], clinical care guidelines stipulate early adoption of insulin and escalation as part of intensifying T2D treatment to aggressively lower glycated haemoglobin (HbA1c) below a general target of $7 \%$ ( $53 \mathrm{mmol} / \mathrm{mol})$. However, it is also understood that insulin initiation is often inappropriately delayed [5], resulting in an unnecessary increased risk of complications and needlessly reduced life expectancy and quality of life [6]. This has been termed 'clinical inertia,' and can be due to a number of factors including clinical concerns (i.e. risk of weight gain, hypoglycaemia, or patient distress), professional concerns (e.g. lack of clinical experience, skills, or confidence in insulin titration), or health system concerns (competing priorities, regulatory or financial constraints, or a lack of impartial continued medical education [CME]) [7-13]. Recently, a systematic review highlighted the global widespread extent of clinical inertia in the management of hyperglycaemia in T2D including studies from the USA (29 studies), Europe (20 studies), and Asia (3 studies) [5]. However, available European studies typical sample from northern European countries including the UK, France, Spain, and the Netherlands [5], with only one study assessing clinical inertia from Central and South-Eastern European regions (one study in Croatia) [14]. Countries in Central and South-Eastern Europe compare poorly to countries in northern Europe due to a number of factors including different healthcare systems, treatment availability, and clinical training. As such, we aimed to comprehensively characterise the prescribing practices of specialist diabetes healthcare professionals across Central and South-Eastern European countries and assess the factors that influence their clinical decision-making regarding insulin initiation in T2D.

\section{Methods}

The Study of Insulin Therapy Initiation in type 2 diabetes in routine clinical Practice (SITIP) is an ongoing multicentre international cross-sectional observational epidemiological study of factors which influence insulin initiation in type 2 diabetes. A cross-sectional survey was performed between September 2017 to January 2018, on 233 actively prescribing specialist diabetes healthcare professionals residing across five Central and South-Eastern European countries (Bulgaria, Croatia, Greece, Hungary, and Slovenia). Study participants were recruited through invitation from participating National Diabetes Associations as well as through the Advances in Diabetes and Insulin Therapy (ADIT) conference database. Following appropriate institutional ethical review, Informed consent was obtained from all individual participants included in the study. The sample $(n=211)$ represents $21.4 \%$ of all 987 prescribing specialist diabetes healthcare professionals within the region (Bulgaria $n=52$ [24.9\%]; Croatia $n=19$ [9.0\%]; Greece $n=51$ [24.3\%]; Hungary $n=73$ [34.9\%]; Slovenia $n=15$ [6.9\%]). Sample size was calculated with regard to confidence intervals (CI) for frequencies: a 95\% CI of 10-15\% for questions answerable was considered narrow enough. This required a sample size of $\sim 200$ persons. A structured 17 -item closed multiple choice questionnaire was designed to collate population demographic information alongside prescription preferences, as well as habits and attitudes towards insulin initiation in T2D using Likert items; the questionnaire was devised by the research team and is shown in supplement 1 .

\section{Statistical analysis}

All analyses were performed with SPSS statistical software, version 23 (IBM SPSS Software, IBM Analytics), with significance set at $p<0.05$. Descriptive statistics were mainly used with continuous variables (i.e. data collected using scaled parameters) and presented as mean \pm standard deviation (SD), unless otherwise specified, and categorical data (i.e. prevalence) presented as absolute number and percentage. The Chi square test was used for comparisons of categorical data (Yates continuity corrected for comparisons with one degree of freedom). Two-sided $p$ values of less than 0.05 were considered significant. With regards to continuous data, regional response rates were weighted to an appropriate share.

\section{Results}

Remarkably, only $9.4 \%$ of healthcare professionals would initiate insulin therapy at the recommended HbA1c threshold of 7-7.9\% ([53-63 mmol/mol]; Table 1). Almost half of the healthcare professionals (47.4\%) would initiate insulin therapy at an HbAlc threshold of $\geq 9.0 \%$ ( $\geq 75 \mathrm{mmol} /$ $\mathrm{mol}$ ), and $8.0 \%$ would not initiate insulin until a threshold of $\geq 10.0 \%$ ( $\geq 86 \mathrm{mmol} / \mathrm{mol}$ ) was reached (Table 1$)$.

As shown in Table 1, when assessing data by region, 77.0\% of respondents from Bulgaria would only initiate insulin therapy when an $\mathrm{HbA} 1 \mathrm{c}$ threshold of $\geq 9.0 \%(\geq 75 \mathrm{mmol} / \mathrm{mol})$ was reached, of which $96.2 \%$ would not initiate insulin until $\geq 10.0 \%$ ( $\geq 86 \mathrm{mmol} / \mathrm{mol}$ ). In Hungary, $26.6 \%$ of respondents would only initiate insulin therapy at an HbA1c a threshold of $\geq 9.0 \%$ ( $\geq 75 \mathrm{mmol} / \mathrm{mol}$ ), of which $85.3 \%$ would not initiate insulin until a threshold of $\geq 10.0 \%(\geq 86 \mathrm{mmol} / \mathrm{mol})$ was reached. Conversely, in Slovenia, $13.3 \%$ of respondents would initiate insulin therapy at an $\mathrm{HbA1c}$ threshold of $\leq 9.0(\leq 75 \mathrm{mmol} / \mathrm{mol})$ and $13.3 \%$ would initiate insulin therapy at an HbAlc threshold of 7-7.9\% (53-63 mmol/mol). 
Table 1 Composite and regional data regarding clinical practice and influences of clinical practice in insulin initiation and alternative therapies in $\mathrm{T} 2 \mathrm{D}$

\begin{tabular}{|c|c|c|c|c|c|c|c|}
\hline & Composite & Bulgaria & Croatia & Greece & Hungary & Slovenia & Test statistic \\
\hline \multicolumn{8}{|l|}{$\mathrm{HbA1c}$} \\
\hline $7.0-7.9 \%$ [53-63 mmol/mol] & $9.4 \%$ & $1.9 \%$ & $10.5 \%$ & $19.2 \%$ & $6.7 \%$ & $13.3 \%$ & - \\
\hline $8.0-8.9 \%$ [64-74 mmol/mol] & $43.2 \%$ & $17.3 \%$ & $47.4 \%$ & $46.1 \%$ & $52.0 \%$ & $73.3 \%$ & - \\
\hline $9.0-9.9 \%$ [75-85 mmol $/ \mathrm{mol}]$ & $39.4 \%$ & $77.0 \%$ & $36.8 \%$ & $28.9 \%$ & $26.6 \%$ & $13.3 \%$ & - \\
\hline$\geq 10.0 \%[\geq 86 \mathrm{mmol} / \mathrm{mol}]$ & $8.0 \%$ & $3.8 \%$ & $5.3 \%$ & $5.8 \%$ & $14.7 \%$ & $0.0 \%$ & - \\
\hline \multicolumn{8}{|c|}{ Clinical barriers to insulin initiation } \\
\hline Hypoglycaemia & $1.84 \pm 1.05$ & $2.11 \pm 1.21$ & $1.80 \pm 1.06$ & $1.56 \pm 0.89$ & $1.85 \pm 1.06$ & $1.79 \pm 0.79$ & $p=0.148$ \\
\hline Weight gain & $2.37 \pm 0.94$ & $2.33 \pm 1.05$ & $2.13 \pm 0.87$ & $2.63 \pm 0.91$ & $2.18 \pm 0.78$ & $2.83 \pm 1.19$ & $p=0.011$ \\
\hline Psychological distress & $3.06 \pm 1.04$ & $2.65 \pm 1.10$ & $3.26 \pm 0.92$ & $2.98 \pm 1.13$ & $3.38 \pm 0.86$ & $2.86 \pm 1.08$ & $p=0.001$ \\
\hline Quality of life & $2.74 \pm 1.05$ & $2.91 \pm 0.96$ & $2.80 \pm 1.08$ & $2.83 \pm 0.97$ & $2.58 \pm 1.13$ & $2.52 \pm 1.17$ & $p=0.344$ \\
\hline \multicolumn{8}{|c|}{ Factors influencing clinical decision-making } \\
\hline Clinical guidelines & $1.52 \pm 0.71$ & $1.54 \pm 0.69$ & $1.70 \pm 0.83$ & $1.34 \pm 0.65$ & $1.58 \pm 0.73$ & $1.62 \pm 0.63$ & $p=0.135$ \\
\hline Health insurance constraints & $2.35 \pm 0.79$ & $2.28 \pm 0.83$ & $2.43 \pm 0.79$ & $2.71 \pm 0.51$ & $2.16 \pm 0.85$ & $2.17 \pm 0.82$ & $p=0.004$ \\
\hline Clinical experience & $2.12 \pm 0.72$ & $2.17 \pm 0.74$ & $1.87 \pm 0.70$ & $1.95 \pm 0.63$ & $2.26 \pm 0.70$ & $2.21 \pm 0.92$ & $p=0.136$ \\
\hline \multicolumn{8}{|c|}{ Factors influencing insulin initiation practices } \\
\hline Clinical experience & $2.07 \pm 0.91$ & $2.22 \pm 0.87$ & $2.04 \pm 1.05$ & $2.02 \pm 0.79$ & $2.08 \pm 1.00$ & $1.72 \pm 0.86$ & $p=0.201$ \\
\hline Information from peers & $3.14 \pm 1.00$ & $3.20 \pm 1.09$ & $3.20 \pm 0.95$ & $3.12 \pm 1.05$ & $3.16 \pm 0.92$ & $2.79 \pm 1.00$ & $p=0.000$ \\
\hline Manufacturer information & $2.77 \pm 1.07$ & $2.57 \pm 1.05$ & $3.09 \pm 0.88$ & $2.88 \pm 1.07$ & $2.66 \pm 1.12$ & $3.21 \pm 0.96$ & $p=0.714$ \\
\hline CME education & $2.02 \pm 1.07$ & $2.02 \pm 1.12$ & $1.67 \pm 0.83$ & $1.98 \pm 1.08$ & $2.09 \pm 1.07$ & $2.28 \pm 1.18$ & $p=0.119$ \\
\hline \multicolumn{8}{|l|}{ Approach to insulin initiation } \\
\hline Basal insulin & $78.6 \%$ & $67.3 \%$ & $88.8 \%$ & $96.0 \%$ & $73.0 \%$ & $75.0 \%$ & - \\
\hline Biphasic insulin & $9.0 \%$ & $25.0 \%$ & $11.2 \%$ & $2.0 \%$ & $0 \%$ & $18.7 \%$ & - \\
\hline Prandial insulin & $0.5 \%$ & $1.9 \%$ & $0 \%$ & $0 \%$ & $0 \%$ & $0 \%$ & - \\
\hline Basal-bolus & $11.9 \%$ & $5.8 \%$ & $0 \%$ & $2.0 \%$ & $27.0 \%$ & $6.3 \%$ & - \\
\hline
\end{tabular}

Note: Continuous data are presented as mean $\pm \mathrm{SD}$, and categorical data are presented as $\%$

Predominantly, basal insulin was primarily selected when initiating insulin therapy (78.6\% of respondents), followed by basal-bolus (11.9\%), biphasic $(9.0 \%)$, and prandial $(0.5 \%)$ insulin.

Psychological distress was recorded as the most prevalent barrier to insulin initiation across the region and risk of hypoglycaemia the least prevalent (Table 1); weight gain was considered secondary to quality of life as a barrier to insulin initiation. Factors influencing clinical decision-making were consistent across the region; health insurance regulations and constraints were listed as the most important determining factor. Conversely, clinical guidelines were the considered the least important factor influencing clinical decisionmaking (Table 1). The most important factor specifically influencing insulin initiation was information from peers, followed by manufacturer information, with CME ranked lowest.

\section{Discussion}

This is the first study to comprehensively examine the prescribing practices and factors of influence of specialist diabetes healthcare professionals regarding insulin initiation in T2D across Central and South-Eastern European countries. In this large $(n=211)$ cohort, we show a high prevalence of clinical inertia, with only $\sim 10 \%$ of prescribers initiating insulin therapy at the recommended $\mathrm{HbAlc}$ threshold of 7-7.9\% (53-63 $\mathrm{mmol} / \mathrm{mol})$. Moreover, almost half the healthcare professionals sampled were orientated towards initiating insulin therapy in patients if an $\mathrm{HbA} 1 \mathrm{c}$ threshold of $\geq 9.0 \%$ ( $\geq 75 \mathrm{mmol} / \mathrm{mol})$ was met, with a further $\sim 10 \%$ only initiating insulin when a threshold of $\geq 10.0 \%$ ( $\geq 86 \mathrm{mmol} / \mathrm{mol}$ ) was reached. Further, we highlight substantial regional differences in the clinical approach to insulin initiation in T2D. For example, almost $80 \%$ of respondents from Bulgaria would only initiate insulin therapy in T2D at an HbA1c a threshold of $\geq 9.0 \%$ ( $\geq 75 \mathrm{mmol} / \mathrm{mol}$ ), of which $\sim 95 \%$ would not initiate insulin until a threshold of $\geq 10.0 \%$ ( $\geq 86 \mathrm{mmol} / \mathrm{mol}$ ) was reached, compared to $<15 \%$ of prescribers in Slovenia. These results indicate 
that only the most poorly controlled patients, as opposed to all patients with evidence of inadequate glycaemic control, are likely to receive timely insulin initiation and that this is in part dependent upon country of residence. Our findings compliment and extend other large multinational studies reporting clinical inertia with regards to insulin initiation in T2D in Europe and elsewhere $[15,16]$.

Preference of basal insulin as the initial choice of insulin therapy is supported by the observation that basal insulin is often judged easier to use and with less risk of hypoglycaemia and weight gain. Further, although a premixed and a basal-bolus regimen have been found to yield greater reductions in $\mathrm{HbA1c}$, compared to basal-only therapy, both are associated with weight gain, increased hypoglycaemia, and inconvenience $[17,18]$.

Previously, physician-, patient-, and healthcare systemrelated factors have been identified as contributing factors to clinical inertia in insulin initiation [19]. In our study, we identified consistent patterns in factors influencing clinical decision-making across the region. Our study participants ranked health insurance regulations and constraints as the most important factor influencing prescription practices, with clinical guidelines ranked as the least important factor. Further, patient distress was highlighted as the most important factor influencing clinical decisions, whereas risk of hypoglycaemia and potential weight gain as the least important factors. In the countries we sampled from, there is restricted regional availability of blood glucose self-monitoring (BGSM) reimbursement [20], and increasing BGSM increases the patient burden of managing T2D [21].

Our data indicates that healthcare professionals within the region turn primarily to peers and manufacturer information to guide and inform insulin initiation practices and that such practices are informed least from CME. Whereas some research has suggested that healthcare professionals perceive industry influence to be low [22], the reality is that the pharmaceutical industry is often a key source of information regarding new products and treatment options [23]. Indeed, several studies have shown that physicians are susceptible to the pharmaceutical industry and interactions with pharmaceutical sale representatives and that this influences prescribing practices [24-26]. In our study, we cannot rule out that the availability of increasing numbers of noninsulin antidiabetic agents and a lack of accessible independent CME could foster a reluctance to use insulin among our healthcare professionals. The concept of evidence-based medicine, defined as the integration of best research evidence with clinical expertise and patient values, is considered an integral part of medical training and should be effectively integrated into independent, non-industry sponsored CME courses [27]. Alarmingly however, our findings suggest that the majority of healthcare professionals within Central and South-Eastern European regions may not implement clinical guidelines and may not use evidence independent of industry to inform T2D treatment. As such, there is an urgent need to provide accessible CME courses independent of industry influence to prescribing specialist diabetes healthcare professionals within this region.

In conclusion, we provide new evidence which highlight a high level of clinical inertia regarding insulin initiation in T2D by prescribing diabetes specialist healthcare professionals in Central and South-Eastern Europe. We provide valuable insight into the factors influencing prescribing practices and clinical decision-making which highlight the urgent need to provide CME courses independent of industry in this region.

Author contributions MDC reviewed the study design, interpreted data, wrote the article and approved the final version. DB designed the study analysed data, drafted the article, and approved the final version. UB designed the study, contributed towards the acquisition of data, revised the article, and approved the final version. LDS designed the study, contributed towards the acquisition of data, and approved the final version of the article. TT reviewed the study design, contributed towards the acquisition of data, and approved the final version of the article. AM reviewed the study design, contributed towards the acquisition of data, and approved the final version of the article. PK reviewed the study design, contributed towards the acquisition of data, and approved the final version of the article. AJ designed the study, contributed towards the acquisition of data, approved the final version of the article, and acts as a guarantor of this work.

Funding This study was funded by AGADA diabetes Education and Research Institute. The funders were involved in the conception of the study and acquisition of study data, but did not influence the study design or analysis or interpretation of results.

\section{Compliance with ethical standards}

Conflict of interest The authors report no conflict of interest.

Ethical standards The article does not contain any studies with animals performed by any of the authors. The study receieved institutional ethical review and all participants provided informed consent. As such, this study conforms to the ethical standards of the Declartion of Helsinki.

Informed consent Informed consent was obtained from all individual participants included in the study

Open Access This article is distributed under the terms of the Creative Commons Attribution 4.0 International License (http://creativeco mmons.org/licenses/by/4.0/), which permits unrestricted use, distribution, and reproduction in any medium, provided you give appropriate credit to the original author(s) and the source, provide a link to the Creative Commons license, and indicate if changes were made. 


\section{References}

1. Ogurtsova K, da Rocha Fernandes JD, Huang Y et al (2017) IDF diabetes Atlas: global estimates for the prevalence of diabetes for 2015 and 2040. Diabetes Res Clin Pract 128:40-50. https://doi. org/10.1016/J.DIABRES.2017.03.024

2. Zoungas S, Arima H, Gerstein HC et al (2017) Effects of intensive glucose control on microvascular outcomes in patients with type 2 diabetes: a meta-analysis of individual participant data from randomised controlled trials. Lancet Diabetes Endocrinol 5:431-437. https://doi.org/10.1016/S2213-8587(17)30104-3

3. Hayward RA, Reaven PD, Wiitala WL et al (2015) Follow-up of glycemic control and cardiovascular outcomes in type 2 diabetes. N Engl J Med 372:2197-2206. https://doi.org/10.1056/NEJMo a1414266

4. Inzucchi SE, Bergenstal RM, Buse JB et al (2015) Management of hyperglycemia in type 2 diabetes, 2015: a patient-centered approach: update to a position statement of the American diabetes association and the European association for the study of diabetes. Diabetes Care 38:140-149. https://doi.org/10.2337/dc14-2441

5. Khunti K, Gomes MB, Pocock S et al (2018) Therapeutic inertia in the treatment of hyperglycaemia in patients with type 2 diabetes: a systematic review. Diabetes Obes Metab 20:427-437. https ://doi.org/10.1111/dom.13088

6. Goodall G, Sarpong EM, Hayes C, Valentine WJ (2009) The consequences of delaying insulin initiation in UK type 2 diabetes patients failing oral hyperglycaemic agents: a modelling study. BMC Endocr Disord 9:19. https://doi. org/10.1186/1472-6823-9-19

7. Polonsky WH, Fisher L, Guzman S et al (2005) Psychological insulin resistance in patients with type 2 diabetes: the scope of the problem. Diabetes Care 28:2543-2545. https://doi.org/10.2337/ DIACARE.28.10.2543

8. Furler J, Spitzer O, Young D, Best J (2011) Insulin in general practice-barriers and enablers for timely initiation. Aust Fam Physician 40:617-621

9. Kunt T, Snoek FJ (2009) Barriers to insulin initiation and intensification and how to overcome them. Int J Clin Pract 63:6-10. https://doi.org/10.1111/j.1742-1241.2009.02176.x

10. Kalra S, Gupta Y (2015) Insulin initiation: bringing objectivity to choice. J Diabetes Metab Disord 14:17. https://doi.org/10.1186/ s40200-015-0146-1

11. Lau ANC, Tang T, Halapy $H$ et al (2012) Initiating insulin in patients with type 2 diabetes. CMAJ 184:767-776. https://doi. org/10.1503/cmaj.110779

12. Home P, Riddle M, Cefalu WT et al (2014) Insulin therapy in people with type 2 diabetes: opportunities and challenges? Diabetes Care 37:1499-1508. https://doi.org/10.2337/dc13-2743

13. Freemantle N, Balkau B, Danchin N et al (2012) Factors influencing initial choice of insulin therapy in a large international non-interventional study of people with type 2 diabetes. Diabetes Obes Metab 14:901-909. https://doi.org/10.111 1/j.1463-1326.2012.01613.x

14. Bralić Lang V, Bergman Marković B, Kranjčević K (2015) Family physician clinical inertia in glycemic control among patients with type 2 diabetes. Med Sci Monit 21:403-411. https://doi. org/10.12659/MSM.892248

15. Valensi P, Benroubi M, Borzi V et al (2008) The IMPROVETM study - a multinational, observational study in type 2 diabetes: baseline characteristics from eight national cohorts. Int J Clin Pract 62:1809-1819. https://doi.org/10.1111/j.1742-1241.2008.01917.x

16. Peyrot M, Rubin RR, Lauritzen T et al (2005) Resistance to insulin therapy among patients and providers: results of the cross-national diabetes attitudes, wishes, and needs (DAWN) study. Diabetes Care 28:2673-2679

17. Meece $\mathbf{J}$ (2018) Basal insulin intensification in patients with type 2 diabetes: a review. Diabetes Ther 9:877-890. https://doi. org/10.1007/s13300-018-0395-3

18. Anyanwagu U, Mamza J, Gordon J et al (2017) Premixed vs basalbolus insulin regimen in type 2 diabetes: comparison of clinical outcomes from randomized controlled trials and real-world data. Diabet Med 34:1728-1736. https://doi.org/10.1111/dme.13518

19. Vora J (2013) Combining incretin-based therapies with insulin: realizing the potential in type 2 diabetes. Diabetes Care 36:S226S232. https://doi.org/10.2337/dcS13-2036

20. Czupryniak L, Barkai L, Bolgarska S et al (2014) Self-monitoring of blood glucose in diabetes: from evidence to clinical reality in Central and Eastern Europe-recommendations from the international Central-Eastern European expert group. Diabetes Technol Ther 16:460-475. https://doi.org/10.1089/dia.2013.0302

21. Chew B-H, Mohd-Sidik S, Shariff-Ghazali S (2015) Negative effects of diabetes-related distress on health-related quality of life: an evaluation among the adult patients with type 2 diabetes mellitus in three primary healthcare clinics in Malaysia. Health Qual Life Outcomes 13:187. https://doi.org/10.1186/s1295 5-015-0384-4

22. Trelle S (2002) Information management and reading habits of German diabetologists: a questionnaire survey. Diabetologia 45:764-774. https://doi.org/10.1007/s00125-002-0807-8

23. Abdul-Ghani MA, Tripathy D, DeFronzo RA (2006) Contributions of B-cell dysfunction and insulin resistance to the pathogenesis of impaired glucose tolerance and impaired fasting glucose. Diabetes Care 29:1130-1139. https://doi.org/10.2337/diaca re. 2951130

24. Lieb K, Scheurich A (2014) Contact between doctors and the pharmaceutical industry, their perceptions, and the effects on prescribing habits. PLoS One 9:e110130. https://doi.org/10.1371/ journal.pone.0110130

25. Fickweiler F, Fickweiler W, Urbach E (2017) Interactions between physicians and the pharmaceutical industry generally and sales representatives specifically and their association with physicians' attitudes and prescribing habits: a systematic review. BMJ Open 7:e016408. https://doi.org/10.1136/bmjopen-2017-016408

26. DeJong C, Aguilar T, Tseng C-W et al (2016) Pharmaceutical industry-sponsored meals and physician prescribing patterns for medicare beneficiaries. JAMA Intern Med 176:1114. https://doi. org/10.1001/jamainternmed.2016.2765

27. Morris MJ, Fewell AE, Oleszewski RT (2012) Evidence-based medicine. South Med J 105:114-119. https://doi.org/10.1097/ SMJ.0b013e31824b197c

Publisher's Note Springer Nature remains neutral with regard to jurisdictional claims in published maps and institutional affiliations. 